the other in a different hospital. Breast feeding and vaginal delivery were not associated with high frequencies of toxin detection in the intensive care unit (data not shown). These findings suggest that nosocomial factors influence the existence of $C$ difficile and the outbreak of diarrhoea associated with $C$ difficile in the intensive care unit.

Latex agglutination test is a simple and quick method compared with enzyme linked immunosorbent assay. ${ }^{4} C$ difficile is recovered from all enterotoxin positive stools and is not detected in enterotoxin negative stools. ${ }^{4}$ The method is sensitive to $15 \mathrm{ng} / \mathrm{ml}$ of enterotoxin, and can be useful for detecting diarrhoea, especially antibiotic-associated colitis for children and for adults, even though $C$ difficile is sometimes found in asymptomatic neonates.
We thank Dr S Chatterjec, Department of Pediatrics, University of Alabama in Birmingham. USA. Mrs N Ushijima, and Mrs M Hamagami for their help.

\section{References}

' Welch DF, Marks MI. Is Clostridium difficile pathogenic in infants? J Pediatr 1982;100:393-5.

2 Donta ST, Myers MG. Clostridium difficile toxin in asymptomatic neonates. J Pediatr 1982;100:431-4.

${ }^{3}$ Libby JM, Donta ST, Wilkins TD. Clostridium difficile toxin A in infants. $J$ Infect Dis 1983;148:606.

${ }^{4}$ Furukawa K, Yamaguchi H, Adachi K, Shirota A. Role of the Clostridium difficile toxin in antibiotics associated colitis - with special reference to the latex fixation test (in Japanese). Stishin Igaku 1983;38:2475-80.

Correspondence to Dr Hiroshi Ushijima, Department of Paediatrics, Teikyo University School of Medicine, Kaga 2-11-1, Habashi-ku, Tokyo 173, Japan.

Received 17 September 1984

\title{
Medical management of bilateral renal malakoplakia
}

\author{
E B CHARNEY, C L WITZLEBEN, S D DOUGLAS, N KAMANI, AND M A KALICHMAN
}

Departments of Pediatrics and Pathology, University of Pennsylvania School of Medicine, and Department of Child Development and Rehabilitation, Pathology, Allergy and Immunology, Children's Hospital of Philadelphia

SUMMARY Renal malakoplakia is reported in an 11 year old girl with myelomeningocele and associated neuropathic bladder. She is the first reported child to have survived bilateral renal malakoplakia with full recovery of renal function after medical management.

Malakoplakia is an unusual chronic inflammatory response primarily occurring in debilitated adults, and characterised by aggregates of macrophages containing concentric calcospherites or MichaelisGutmann bodies. An immunologic defect of ineffective macrophage phagocytic ability is believed to contribute to its pathogenesis. Although frequently affecting the collecting system of the urinary tract, it only rarely involves renal parenchyma. Earlier published reports ${ }^{12}$ state that unilateral renal involvement requires nephrectomy and bilateral involvement is invariably fatal. We report a child with bilateral renal malakoplakia in whom conservative medical management resulted in survival and normal renal function.

\section{Case report}

An 11 year old girl was admitted to this hospital with a five day history of fever and abdominal pain. Past medical history included myelomeningocele repair and ventriculoatrial shunt for hydrocephalus at birth with a shunt revision at age 9 years and insertion of a Brantley-Scott prosthetic urethral sphincter for urinary incontinence at age 8 years. According to parental reports, the child had not complied in deactivating the sphincter regularly during the previous few months. Two years before hospital admission her intravenous pyelogram had been normal, blood urea nitrogen (BUN) was $3.9 \mathrm{mmol} / \mathrm{l}(10.9$ $\mathrm{mg} / 100 \mathrm{ml})$ and serum creatinine was $44.2 \mu \mathrm{mol} / \mathrm{l}$ $(0.5 \mathrm{mg} / 100 \mathrm{ml})$.

Physical examination on admission showed a toxic appearing child with temperature of $38.2^{\circ} \mathrm{C}$; heart rate 136 /minute; respiratory rate 24 /minute; blood pressure $132 / 80 \mathrm{~mm} \mathrm{Hg}$ and bilateral flank tenderness with diffuse abdominal pain. Laboratory evaluation on admission included the following values: haemoglobin $10 \cdot 1 \mathrm{~g} / \mathrm{dl}$; haematocrit $28 \%$, white cell count $5.7 \times / 10^{9}$ l with $77 \%$ segmented neutrophils; $1 \%$ eosinophils; $19 \%$ lymphocytes and $3 \%$ monocytes; and platelets $98 \times 10^{9} \mathrm{l}$; erythrocyte sedimentation rate $63 \mathrm{~mm}$ in the first hour. Serum sodium was $137 \mathrm{mmol} / \mathrm{l}$; potassium $2.8 \mathrm{mmol} / \mathrm{l}$; chloride $103 \mathrm{mmol} / \mathrm{l}$; bicarbonate $16 \mathrm{mmol} / \mathrm{l}$; BUN $23 \mathrm{mmol} / \mathrm{l}(61 \cdot 3 \mathrm{mg} / 100 \mathrm{ml})$; and serum creatinine $256 \mu \mathrm{mol} / \mathrm{l}(2-9 \mathrm{mg} / 100 \mathrm{ml})$. Urine obtained by bladder catheterisation $(800 \mathrm{cc})$ had a specific gravity of $1 \cdot 010$, trace protein, and numerous white 
and red blood cells without cellular casts. Urine culture grew Escherichia coli $(2000$ colonies $/ \mathrm{ml})$ and several blood cultures were sterile. Initial treatment consisted of intravenous ampicillin for presumed pyelonephritis and bladder drainage with an indwelling Foley catheter.

The urine cultures became sterile during the initial 10 day course of antibiotic treatment; BUN dropped to $5.3 \mathrm{mmol} / \mathrm{l}(14.8 \mathrm{mg} / 100 \mathrm{ml})$ and the creatinine concentration to $88 \mu \mathrm{mol} / \mathrm{l}(1 \mathrm{mg} / 100 \mathrm{ml})$ within several days of bladder drainage. Despite this, the remainder of her 10 weeks in hospital was marked by persistence of fever $\left(38.5\right.$ to $\left.39.0^{\circ} \mathrm{C}\right)$. Additional diagnostic studies showed bilateral hydronephrosis on an intravenous pyelogram, bilateral vesicoureteral reflux on a voiding cystourethrogram, and diffusely increased bilateral renal uptake and enlargement on a gallium-67 citrate scan.

An open renal biopsy was performed during the ninth week in hospital, and histology showed malakoplakia (Figs. 1 and 2). She was begun on trimethoprim $160 \mathrm{mg} /$ sulfamethoxazole $800 \mathrm{mg}$ daily, one week after the biopsy, and within several days she became afebrile. Immunologic investiga-

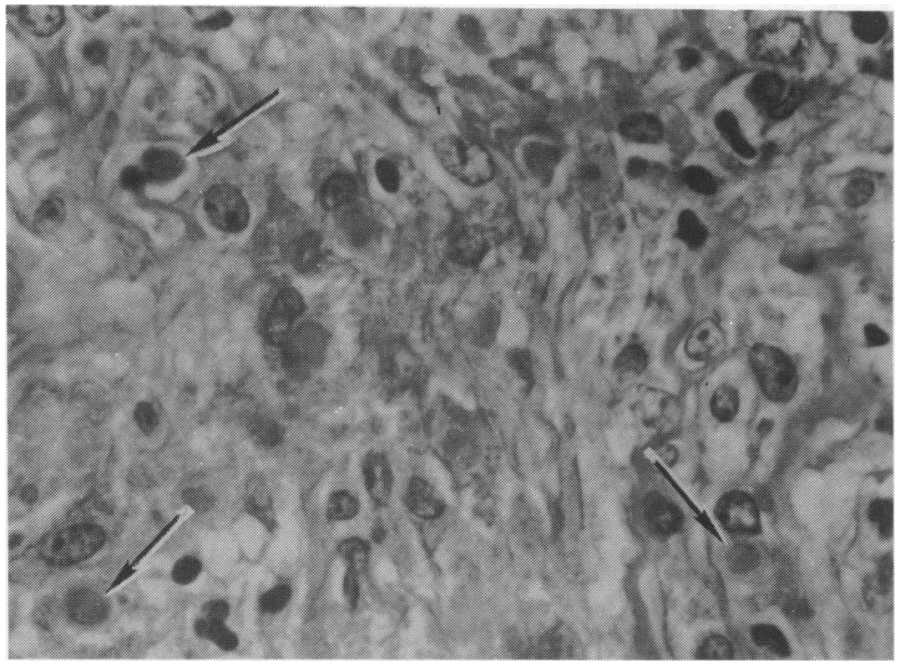

Fig. 1 Light micrograph of renal biopsy showing inflammatory reaction. A few of the numerous Michaelis-Gutmann bodies are indicated by arrows. (Haematoxylin and eosin).

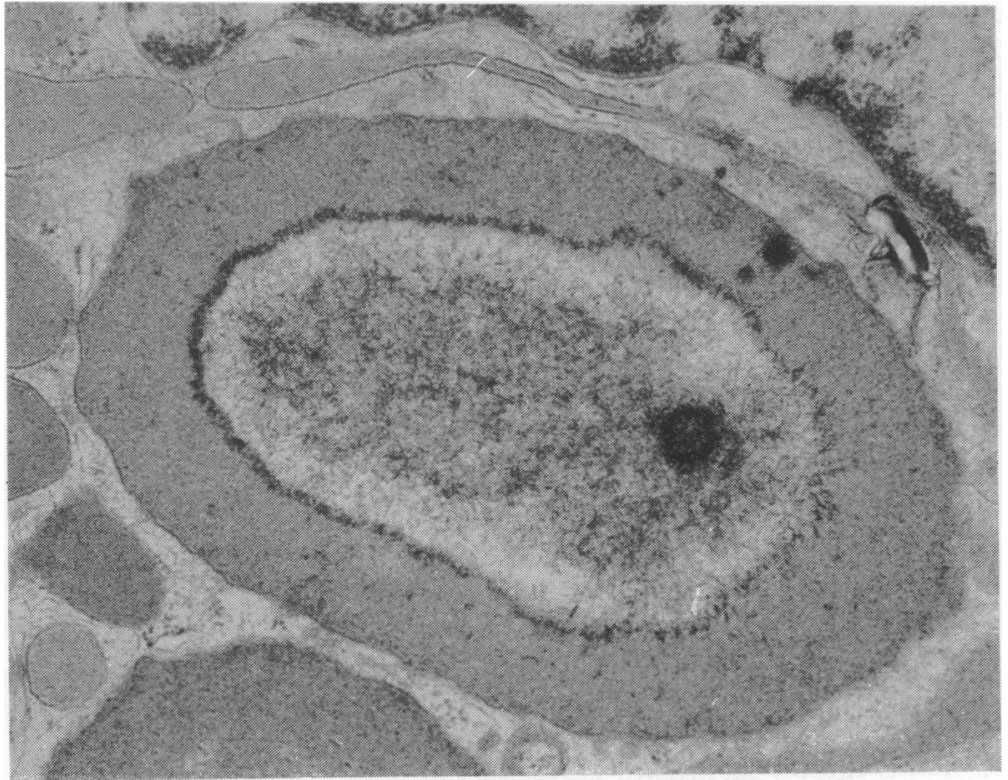

Fig. 2 Electron micrograph of portion of macrophage. Michaelis-Gutmann body, with central nidus of hydroxyapatite and surrounding layers of varying density, is in centre of field. Portion of nucleus is in the top right corner. 
tion done six weeks after beginning this treatment including assays for monocyte bactericidal activity and superoxide anion release were normal. During seven months' follow up she has been in good health while maintaining normal renal function with BUN $3.2 \mathrm{mmol} / \mathrm{l}(8.9 \mathrm{mg} / 100 \mathrm{ml})$ and creatinine $61 \mu \mathrm{mol} / \mathrm{l}$ $(0.7 \mathrm{mg} / 100 \mathrm{ml})$. She has been maintained on trimethroprim/sulfamethoxazole and a regular clean intermittent bladder catheterisation home programme throughout this time.

\section{Discussion}

Malakoplakia, first described in 1902 by Michaelis and Gutmann, ${ }^{3}$ grossly, consists of variably sized yellow-brown soft plaques. The term malokoplakia is, therefore, derived from the Greek words 'malakos' (soft) and 'plakos' (plaque). Microscopically it is characterised by dense aggregates of large mononuclear phagocytes or histocytes (von Hansemann cells) with an eosinophilic granular cytoplasm that stains positive with periodic acid Schiff reaction. These histocytes also contain the characteristic intracytoplasmic laminated basophilic calcospherules, or Michaelis-Gutmann bodies. (Fig. 1). When fully developed the bodies have a characteristic electron microscopical appearance, with a central core of dense crystals, a light halo, and an outer lamellar crystal formation. (Fig. 2)

The clinical manifestations of renal malakoplakia are often initially indistinguishable from an ordinary urinary tract infection. The fever and flank pain, however, will characteristically persist, as it did in our patient, in the presence of seemingly appropriate intravenous antibiotic treatment and sterile urine cultures. The renal insufficiency of renal malakoplakia may occur in either the presence or absence of urinary tract obstruction. Our patient's initial renal insufficiency was associated with obstruction. This was apparent as her azotaemia resolved when adequate bladder drainage was accomplished through an indwelling Foley catheter. Urinary retention with poor bladder emptying was most probably secondary to the child's noncompliance at home and at school in deactivating her artificial urethral sphincter regularly.

The pathogenesis of malakoplakia remains unknown, yet it is generally considered that the lesion is associated with a defect in the ability of macrophages to digest phagocytosed bacteria, particularly coliform organisms. ${ }^{4}$ It is the calcification of these incompletely digested organisms that are thought to produce the Michaelis-Gutmann bodies.

Investigation into the medical management of malokoplakia has recently been directed towards modifying the defective phagocytic ability of the patients macrophages. Urecholine, a cholinergic agonist, has been shown to improve $E$ coli bactericidal activity of monocytes in an adult with rectal malakoplakia, ${ }^{5}$ while the intracellularly active antibiotic trimethroprime/sulphamethoxazole improved macrophage bacterial digestion in an adult with ureteral and retroperitoneal malakoplakia. ${ }^{6}$ In our patient, monocyte bactericidal activity was normal as determined by an in vitro bactericidal asssay and monocyte superoxide production. Since she was already on trimethroprime/sulphamethoxazole treatment when the monocyte studies were performed, and has required continued treatment for urinary prophylaxis, we can only speculate that either defective bactericidal activity may not be a consistent finding in patients with malakoplakia or monocyte dysfunction was improved by the use of the intracellular active antibiotic, or both.

Recognition of renal malakoplakia as both a clinical and pathologic entity is particularly important for those physicians caring for children with neuropathic bladders, in which coliform infection may be quite common. The vast majority of the childhood population with neuropathic bladders is made up of children with myelomeningocele. Through recent medical and surgical advances, more and more of these children are surviving through adolescence and into adulthood. As future cases of renal malakoplakia may be identified among these and other children, our patient serves to illustrate that surgical management may not always be necessary. It should only be considered for patients in whom renal damage is progressive in spite of medical management. This medical management may require trials of cholinergic agonists or intracellularly active antibiotics, or both.

\section{References}

${ }^{1}$ DeRidder P, Koff S, et al. Renal malakoplakia. J Urol 1977;117:428-31.

2 Loon Ho K, Rassekh Z, Hai Nam S. Bilateral renal malakoplakia. Urology 1979;13:321-3.

3 Michaelis L, Gutmann C. Ueber einschlusse in blasentumoren. Zeitschrift für Klinische Medizin 1902;47:208-15.

${ }^{4}$ Lou TY, Teplitz C. Malakoplakia: pathogenesis and ultrastructural morphogenesis: a problem of altered macrophage (phagolysosomal) response. Hum Pathol 1974;5:191-207.

5 Abdou NI, NaPombejara C, Sagawa A, et al. Malakoplakia: evidence for monocyte lysosomal abnormality correctable by cholinergic agonists in vitro and in vivo. $N$ Engl J Med 1977;297:1413-9.

6 Maderazo EG, Berlin BB, Morhardt C. Treatment of malakoplakia with trimithoprim-sulfamethoxazole. Urology 1979;13: $70-3$.

Correspondence to Dr E Charney, Children's Hospital of Philadelphia, 34th Street and Civic Center Blvd, Philadelphia, PA 19104, USA.

Received 15 October 1984 